\title{
Study on Appraisal of Real Estate Industry Based on Appraisal of Real Estate
}

\author{
Lin $\mathrm{Xu}^{1}$, Yan $\mathrm{Xiao}^{2}$ \\ ${ }^{1}$ Urban Vocational College of Sichuan, Chengdu, 610101, China \\ ${ }^{2}$ Management School, Chongqing Technology and Business University, Chongqing, 400067, China
}

Keywords: Real estate, Economic structure, Industrial appraisal, Study

\begin{abstract}
In recent years, China's economic level has improved continually, which drives development of science and technology. Meanwhile, real estate industry gradually becomes an important economic pillar of China, and it is one of fundamental and leading industries. Real estate is a significant product of market economy, and its assessment function expands continuously and gradually develops to diversity. Real estate industry involves production, circulation and consumption fields, and can effectively boost financial income and improve residents' life quality. Therefore, real estate industry plays a significant role in modern economic society.
\end{abstract}

\section{Introduction}

Since the $21^{\text {st }}$ century, real estate market in Chinese mainland has been reformed correspondingly, and gradually highlights its important status in real estate investment fever. Meanwhile, the industries related to real estate start to develop rapidly. The most obvious phenomenon is "exhibition economy” . In China, “housing exhibition” and “China International Real Estate \& Architectural Technology Fair” appear frequently. In large ad medium cities, the frequency of housing exhibitions is on the rise. Just in this fever, housing price rises continuously. Meanwhile, the development of real estate industry is key growth point of Chinese economy. It can not just effectively boost people's living standard, but also ensures stable development of national economy and drives development of relevant industries. But, some defects also exist behind rapid development of real estate industry and need to be solved urgently.

\section{Real estate appraisal}

Real estate appraisal means professional real estate appraisal personnel strictly abide by recognized appraisal principle and perform relevant appraisal procedure according to establish appraisal objective, use scientific and rational appraisal ways to overall analyze and study the factors influencing the value of appraisal objects, finally estimate and predict the value of appraisal objects at the specific time ${ }^{[1]}$. Real estate appraisal perfectly combines art and science and can really express and reveal real estate price.

Real estate brokers can provide clients with real estate information and intermediate agency services. The institutions engaging in such activity is called brokerage agency.

Real estate appraisal and real estate brokers can provide parties with relevant information, technology, laws, regulations and policy services in real estate transaction process. Real estate appraisal and brokerage agencies cooperate during real estate investment, development and completion.

\section{Case analysis}

This paper takes sale of residential property of a real estate developer as the specific case for analysis. The residential property was sold to the owner. The owner wanted to transfer the residential property after it was used for two years. So, the owner entrusted an agency to sell the residential property. The agency sought customers from customer data mastered by the agency and directly 
contacted with the buyers with buying intent according to the information and data about the residential property provided by the owner and the expected sale price. In the contacting process, the conditions of residential property should be explained in detail, and the agency should let the buyer deeply know the conditions through site investigation. Besides, the agency needs to actively organize and represent both parties for negotiation until the transaction price is consistent. Then, when the buyer purchases the residential property, it is necessary to apply for mortgage loan from the bank and accepts bank's commission to estimate residential property and regard it as important reference basis for the bank to issue the loan. After site instigation and data query, it is necessary to correctly choose evaluation method. At the same time, the appraisal agency should provide objective evaluation value for the bank and deem it as reference value of bank loan.

The above case can reflect different service links, objects and specific services of real estate appraisal and agency in the whole real estate transition process. Next, detailed analysis will be carried out for other possible problems existing in the above case.

When the developer sells residential property, the agency may accept a commission to offer corresponding services for overall real estate sales. When the owner buys the residential property, it is also possible to apply for mortgage loan from banks. Meanwhile, banks will also propose commission to the appraisal agency and appraise the price of residential property as specific reference value for bank loan. In the above case, the buyer and the seller will entrust an appraisal agency before the transaction or in the transaction process, and require scientific and reasonable assessment of residential property as the reference in actual transaction. The owner of residential property may put forward a commission to lease the residential property. Similarly, the appraisal agency may accept this commission and rationally estimate according to corresponding rent. In addition, when the buyer cannot repay the loan, the agency will accept corresponding commission to dispose the asset so as to repay bank loan in time. Meanwhile, real estimate appraisal institution may accept the commission to rationally dispose the asset. Thus, in real estate transaction process, appraisal institution and agency always exist, and the cooperation between the two is very close.

\section{Problems in cooperation between real estate appraisal institution and agency}

The above case has certain universality. Next, possible problems in this case are analyzed comprehensively in detail.

Firstly, disputes between both parties due to transaction price and appraisal price ${ }^{[2]}$. In actual real estate transaction process, the brokerage agency confirms the transaction price between the buyer and the seller, and it serves as the actual transaction price. But, such transaction price is mainly depended on traders' preference and mentality as well as market understanding degree and bargaining ability. However, the evaluated price is given by the appraisers based on objective and fair evaluation of the real estate, and is unrelated to traders' factors. In the appraisal process, the appraisal agency needs to know specific transactions from the brokerage agency, to carefully analyze specific transaction situation, to study positive and negative effects of transaction situation on the evaluated value and to rationally adjust evaluated price of the real estate finally.

Secondly, connotation difference of real estate transaction price and evaluated price. The difference of real estate transaction price and evaluated price often appears in evaluation of transaction reference. In the above case, transaction price of brokerage agency involves residential property, internal decoration, furniture and household appliances etc. But, in the appraisal work with the main purpose of mortgage, decoration will not be paid attention to, and the influence of decoration on value evaluation will not be valued. Thus, in actual evaluation work, additional value of decoration part needs to be eliminated.

When the above situation appears, the brokerage agency will consider estimated value of appraisal agency is not objective, fails to really reflect market situation and will suffer customers' dissatisfaction. More seriously, the loan may not meet customers' requirements so that the transaction cannot be conducted normally. The primary cause for this phenomenon is that both parties fail to well communicate in the cooperation process, do not comprehensively know specific business and cannot introduce to customers in detail. 
Thirdly, reference case provided is not true. When real estate appraisal institution evaluates the residential property, it is required to extensively gather price data of same kind of residential properties, carry out overall analysis and adjustment and then gain fair and objective real estate appraisal value ${ }^{[3]}$. Because in current stage, Chinese brokerage agencies are mainly based on district operation mode, they will master massive transaction data and information about the real estates in the district so that the appraisal agency will consult corresponding information and data to the brokerage agency. However, the e brokerage agency will offer untrue transaction information and data and mislead appraisal personnel in order to fully meet the limit of customer loan. Thus, the final real estate appraisal and actual market price have large differences.

Te above problem is not just because the problem of the brokerage agency. The major cause is that the database of appraisal agency is not sound and fails to be updated in time. Thus, completion of real estate appraisal in a short time will lack certain market information so that brokerage agency will mislead appraisal personnel. In addition, scientific and reasonable screening and proper adjustment of the materials are not done from professional perspective.

\section{Effective approaches to solve cooperation between real estate appraisal institution and brokerage agency}

In the above case, problems appear during cooperation between real estate appraisal institution and brokerage agency, and these problems directly influence traders' economic benefit, lead to unfair influence, damage market competition order to some extent and seriously affect external image of real estate industry. In addition, negative influence is also caused on long-term effect of real estate appraisal institution and brokerage agency.

Partly cause for the above problem is that both organizations have no mutual understanding and effective communication, and the brokerage agency explains to customers objectively without correctly understanding and cognition of technical concept of appraisal agency. Moreover, the above problem is partly because the appraisal agency fails to deeply know transaction situation of brokerage agency in actual transaction process. Thus, the transaction price cannot be correctly analyzed and judged, and real cases cannot be offered ${ }^{[4]}$. Meanwhile, the above problem is partly because both parties fail to cooperate well in transaction process and give rise to serious economic loss to traders. The above causes need to be rationally improved and even completely eradicated in future work.

Relevant government sectors and real estate industry association pay great attention to the above problems, and actively propose feasible solutions, this paper overall explains real estate industry from the perspective of real estate employees and institutions.

Firstly, communication and exchange between real estate appraisal institution and brokerage agency should be continuously enhanced, and specific job contents of each other should be mastered. Besides, the questions on both real estate information and technology proposed by customers, should be accurately explained to make sure customers are satisfied.

Secondly, real estate appraisal institution needs to actively establish relevant database, and to update information and data in database in time. But, database update needs coordination of brokerage agency so as to offer fair, objective and accurate real estate transaction information for database establishment. Meanwhile, it is necessary to overall explain specific transaction conditions.

Thirdly, the institution needs to carry out strict management of daily work of internal employees, and conduct professional ethics training at regular intervals. Real estate industry association strictly supervises daily performance of real estate employees and utilizes specific specifications of real estate industry to standardize employees' behaviors. However, real estate appraisal institution and real estate brokerage serve as daily workplace of employees, and employees perform corresponding duties at their own posts and always enjoy certain rights. Thus, real estate appraisal institution and real estate brokerage agency need to train business ability and professional ethics of internal employees so as to cultivate their consciousness of responsibility and boost their working ability and business level continuously.

Fourthly, both organizations need to create customer compliant channel, handle and solve specific complaints in time ${ }^{[5]}$. Because real estate appraisal institution and real estate brokerage agency belong 
to the tertiary industry, service is the important job content and aim. It is thus required to continuously meet customers' demand and offer superior services. But, in actual organizations, department setting is not reasonable, and mostly based on business department, but corresponding after-sale department and other necessary departments are not set up, like customer compliant department. Thus, customers cannot complain problems in time, let alone solve problems in time. This brings certain troubles to customers and seriously affects the image of both organizations. So, establishment of customer compliant channel owns important practical significance.

\section{Conclusions}

In general, since Chinese real estate appraisal and transaction market develops to maturity gradually, and comprehensive quality of related employees improves obviously. Hence, it is very necessary for real estate insiders to deeply dig and explore cooperation problems of real estate appraisal institution and brokerage agency. In addition, it is more necessary to deeply know market conditions, perfect market, create fair, just and transparent real estate market for consumers and make consumers to carry out real estate transaction securely. This paper sets forth related concepts of real estate appraisal, conduct all-round analysis of specific case, finds out problems existing in cooperation between real estate appraisal institution and brokerage agency and proposes corresponding solutions to make sure both organizations cooperate stably in the future. This paper has important active significance for development of real estate industry and contributes to meetting consumers' demand.

\section{References}

[1] Deng Xiong, Influence of real estate on economic growth and economic growth. Western Finance, 2015(2):14-18,28.

[2] Shang Chunfang, Li Jinwei and Cheng Jingmin et al., Challenge and outlook of macro-economic situation on real estate appraisal industry. 2013 collected papers of China Institute of Real Estate Appraisers and Agents, 2013:46-49.

[3] Qu Weidong, Ye Bingyang, opportunities and challenges for appraisal industry brought by development and change of real estate market. 2012 collected papers of China Institute of Real Estate Appraisers and Agents, 2012:1-8.

[4] Qi Weiyuan, Innovation of expanding paths of appraisal industry to adapt real estate securitization. 2014:198-202.

[5] Bai Jie, On survival and development of real estate appraisal intermediary agent. China Science \& Technology Panorama Magazine, 2010(24):309. 